\title{
Relationship between periodontal disease and cardiovascular risk factors among young and middle-aged Brazilians. Cross-sectional study
}

\author{
Relação entre doença periodontal e fatores de risco cardiovascular em brasileiros \\ jovens e de meia-idade. Estudo transversal
}

\author{
Alessandra Carvalho Goulart', Favius Armani", Astrid Marie Arap"', Thais Nejm", Juliana Barros Andrade", \\ Henry Bittar Bufarah", Danielli Haddad Syllos Dezen'v
}

Health Promotion and Check-up Center, Hospital Sírio Libanês, São Paulo (SP), Brazil

'MD, PhD. Clinical Epidemiologist, Health Promotion and Check-up Center, Hospital Sírio Libanês, São Paulo (SP); and Clinical Epidemiologist, Center for Clinical and Epidemiological Research, Hospital Universitário, Universidade de São Paulo (USP), São Paulo (SP), Brazil.

"DDS. Dentist, Health Promotion and Check-up Center, Hospital Sírio Libanês, São Paulo (SP), Brazil.

"'MSc. Dentist, Health Promotion and Check-up Center, Hospital Sírio Libanês, São Paulo (SP), Brazil.

"MD. Dentist, Health Promotion and Check-up Center, Hospital Sírio Libanês, São Paulo (SP), Brazil.

\section{KEY WORDS:}

Obesity.

Periodontitis.

Periodontal diseases.

Cross-sectional studies

Risk factors.

\section{PALAVRAS-CHAVE:}

Obesidade.

Periodontite.

Doenças periodontais.

Estudos transversais.

Fatores de risco.

\begin{abstract}
CONTEXT AND OBJECTIVE: It has been suggested in the literature that periodontal disease (PD) is associated with cardiovascular risk. The objective of this study was to appraise the relationship between periodontal disease (gingivitis and periodontitis) and traditional cardiovascular risk factors (obesity, hypertension, dyslipidemia, diabetes and metabolic syndrome) among young and middle-aged adults attended at a health promotion and check-up center in the city of São Paulo, Brazil.

DESIGN AND SETTING: Cross-sectional study at the Health Promotion and Check-up Center of Hospital Sírio-Libanês, São Paulo, Brazil.

METHODS: We consecutively evaluated 539 subjects without prior cardiovascular disease who were seen within a health promotion program that included cardiovascular and dental evaluation between February and November 2012. Odds ratios (OR) with respective 95\% confidence intervals (95\% Cl) for the association between PD and cardiovascular risk factors were ascertained through multinomial logistic regression. RESULTS: In this sample of mean age 45 years (standard deviation, $S D \pm 8.8$ ), which was $82 \%$ male, we found PD in $63.2 \%$ (gingivitis 50.6\% and periodontitis 12.6\%). Individuals with PD were older, more obese (without PD 15.2\%; versus gingivitis 22.1\% and periodontitis 32.4\%) and more diabetic (without PD 5.1\%; versus gingivitis $4.8 \%$ and periodontitis 13.2\%), compared with those without PD. Among all cardiovascular risk factors evaluated, obesity was associated with periodontitis (multivariate $\mathrm{OR}, 2.36$; $95 \% \mathrm{Cl}, 1.23-$ 4.52). However, after additional adjustment for oral hygiene, this finding was no longer significant (multivariate $\mathrm{OR}, 1.63 ; 95 \% \mathrm{Cl}, 0.79-3.37)$.

CONCLUSIONS: We did not find any significant associations between cardiovascular risk factors and periodontal disease in this sample.
\end{abstract}

\section{RESUMO}

CONTEXTO E OBJETIVO: A literatura sugere que doença periodontal (DP) está associada ao risco cardiovascular. O objetivo deste estudo foi avaliar a relação entre doença periodontal (gengivite e periodontite) e fatores de risco cardiovasculares tradicionais (obesidade, hipertensão, dislipidemia, diabetes e síndrome metabólica) em adultos jovens e de meia-idade atendidos em um centro de promoção da saúde e check-up na cidade de São Paulo, Brasil.

TIPO DE ESTUDO E LOCAL: Estudo transversal no Centro de Promoção de Saúde e check-up do Hospital Sírio-Libanês, São Paulo, Brasil.

MÉTODOS: Avaliamos consecutivamente 539 indivíduos sem doença cardiovascular diagnosticada, observados em um programa de promoção da saúde que incluiu avaliação cardiovascular e odontológica de fevereiro a novembro de 2012. Razões de chances (RC) com respectivos intervalos de confiança de 95\% (IC 95\%) para a associação entre DP e fatores de risco cardiovascular foram calculadas por regressão logística multinomial.

RESULTADOS: Nesta amostra de pessoas com idade média de 45 anos (desvio padrão, DP $\pm 8,8$ ), 82\% de homens, encontramos $63,2 \%$ de casos de DP (50,6\% de gengivite e periodontite $12,6 \%$ ). Indivíduos com DP eram mais velhos, mais obesos (sem DP 15,2\%; versus gengivite $22,1 \%$ e periodontite $32,4 \%$ ) e mais diabéticos (sem DP 5,1\%; versus gengivite 4,8\% e periodontite 13,2\%) comparados com aqueles sem DP. De todos os fatores de risco cardiovascular avaliados, a obesidade foi associada à periodontite (RC multivariada, 2,36; IC 95\%, 1,23-4,52). No entanto, após ajuste adicional para higiene bucal, esse achado não foi mais significativo (RC multivariada, 1,63; IC 95\%, 0,79-3,37).

CONCLUSÕES: Não encontramos associações significativas entre fatores de risco cardiovascular e doença periodontal nesta amostra. 


\section{INTRODUCTION}

Recent evidence has suggested that periodontal disease (PD) is an emerging risk factor for fatal and non-fatal cardiovascular outcomes. ${ }^{1-5}$ Pooled data from a systematic review found that PD was independently associated with increased risk of coronary heart disease (CHD), with risk estimates ranging from 1.24 (95\% confidence interval, CI, 1.01-1.51) to 1.34 (95\% CI, 1.10-1.63). ${ }^{1}$

In the Normative Aging and Dental Longitudinal Study, which was conducted on 1,203 men who were followed up for 35 years, chronic periodontitis was also associated with increased incidence of CHD, particularly among individuals younger than 60 years of age, independent of established cardiovascular risk factors (CVRFs) such as dyslipidemia, diabetes and hypertension. In that study, a hazard ratio (HR) of 2.12 (95\% CI, 1.26-3.60) from comparing the highest versus the lowest category of radiographic bone loss (which is a measurement of advanced PD) was reported for individuals younger than 60 years, but not for those older than 60 years. ${ }^{2}$ Moreover, PD is also associated with all-cause and cardiovascular disease (CVD) mortality. ${ }^{3,4}$ In the VA Normative Aging and Dental Longitudinal Study, for each $20 \%$ increase in mean whole-mouth radiographic alveolar bone loss (ABL), the risk of death increased by $51 \%{ }^{3}$

In the National Health and Nutrition Examination Survey III (NHANES III), prospective evaluations were performed on 10,849 participants, and 3,105 and 561 individuals were identified as having moderate and severe $\mathrm{PD}$, respectively. The highest HR for all-cause mortality (hazard ratio (HR), 1.64; 95\% CI (confidence interval), 1.25-2.15), and particularly for CVD mortality (HR, 2.13; 95\% CI, 1.37-3.31), was reported among individuals with severe $\mathrm{PD}$, again only for younger individuals (aged 30-64 years). ${ }^{4}$

In the Women's Health Study, CVD outcomes were found more often among women with PD (incidence and prevalence). The incidence rates for PD were highest for major CVD (adjusted HR, 1.42; 95\% CI, 1.14-1.77), for MI ( myocardial infarction) (HR, 1.72; 95\% CI, 1.25-2.38), for ischemic stroke (HR, 1.41; 95\% CI, 1.02-1.95) and for total CVD (HR, 1.27; 95\% CI, 1.06-1.52).

Furthermore, recent studies reported positive associations between periodontal disease and subclinical atherosclerosis, mostly reporting alterations in carotid intima-media thickness among individuals with $\mathrm{PD} .^{6-8}$ The inflammation process of $\mathrm{PD}$ may trigger systemic inflammation that could be involved in the progression of atherosclerosis and consequently in CVD outcomes such as myocardial infarction or stroke. ${ }^{9}$ However, it is not totally clear what the causal pathway between PD and CVD risk is. ${ }^{10}$ Many observational studies have evaluated the association between different levels of periodontal disease and traditional CVRFs, such as obesity or correlated measurements, ${ }^{11-21}$ while others have reported some association with diabetes ${ }^{22}$ or metabolic disorders. ${ }^{23,24}$ Among these studies, most reported an increased odds ratio (OR) for the relationship between obesity and periodontal disease..$^{13,15,17-21}$
Despite the importance of PD as a potential emerging cardiovascular risk, ${ }^{25,26}$ there is a paucity of systematic data that might justify inclusion of dental examination as a screening strategy for intermediate to high-risk individuals such as those presenting obesity or diabetes and those with a previous family history of CHD., ${ }^{1,27}$

Moreover, there are no studies that included comprehensive dental examination, including data on oral hygiene and cardiovascular risk factor evaluation at the same time, in a young to middleaged population. Such populations probably present the greatest susceptibility to CVD risk in the presence of PD. ${ }^{2,4}$

\section{OBJECTIVE}

We aimed to appraise the relationship between periodontal disease (gingivitis and periodontitis) and traditional CVRFs (obesity, hypertension, dyslipidemia, diabetes and metabolic syndrome) among young and middle-aged adults who were attended at a health promotion and check-up center in the city of São Paulo, Brazil.

\section{METHODS}

\section{Study design and sample}

This was a cross-sectional study conducted on a consecutive sample of all consecutive young and middle-aged individuals who were free from CVD (myocardial infarction, coronary revascularization, heart failure and stroke) and who sought attendance through a health promotion program between February and November 2012. All of them underwent standard cardiovascular and dental screening. It should be noted that the normal attendance rate at this check-up center is approximately 300 adults older than 18 years of age per month.

The Health Promotion and Check-up Center forms part of the complex of Hospital Sírio-Libanês (Syrian-Lebanese Hospital), which is a tertiary-level private hospital located in the central zone of the city of São Paulo, one of most populous cities and the most important financial center of Brazil. The population regularly attended at this check-up center is mainly composed of active middle-aged male workers.

The study protocol was approved by the Institutional Review Board that addresses research on human participants, in accordance with the Declaration of Helsinki. All the participants signed an informed consent form.

\section{Data-gathering}

All individuals underwent a standard evaluation focusing on cardiological assessment and clinical examinations that were based on screening strategies for the general population recommended by the United States Preventive Services Task Force and the Centre for Health Promotion Canada. ${ }^{28,29}$ 
Sociodemographic data such as age (mean \pm standard deviation) and educational level (up to completed high school or completed undergraduate course), data on CVRFs (hypertension, dyslipidemia, diabetes, obesity and metabolic syndrome) and lifestyle information, which included smoking status (never, former and current) and alcohol consumption (at least once a week), were all evaluated by cardiologists who were specialists in CVD screening. The screening was done in accordance with standardized protocols developed by the check-up center.

\section{Oral health examination}

Five dentists at our check-up center, who had been trained by a specialist in periodontal diseases, were responsible for replicating a standardized protocol for oral examinations, in order to maintain the homogeneity of the data gathered.

Information on oral hygiene was obtained using a questionnaire that asked for the following data: frequency of toothbrushing, use of dental floss and presence of halitosis. Oral hygiene was categorized into three levels as follows: poor (0-1 toothbrushing/day + 0-1 dental flossing/day + presence or absence of halitosis; score 0-3); moderate ( 2 toothbrushings/day $+0-2$ dental flossings/day + presence or absence of halitosis; score 4-5); or good ( $\geq 3$ toothbrushings/day + $\geq 3$ dental flossings/day + absence of halitosis; score $\geq 6$ ).

All the individuals screened also underwent an oral evaluation using a periodontal probe to measure pocket depths around each tooth, in order to establish the state of health of the periodontium. All teeth were examined at six different sites (mesiobuccal, mediobuccal, distobuccal, mesiolingual, mediolingual and distolingual). All sites were probed and a pocket was considered to be present when the probing depth was $4 \mathrm{~mm}$ or greater at at least one site. Periodontal disease outcomes were categorized as follows:

1. Gingivitis: defined as gingival bleeding after 10 seconds of probing;

2. Periodontitis: defined as presence of four or more teeth with one or more sites with probing pocket depth greater than or equal to $4 \mathrm{~mm}$ and clinical attachment loss $\geq 3 \mathrm{~mm}$; and

3. Absence of periodontal disease (reference group): no signs of inflammation or pocketing. ${ }^{30}$

Based on this oral examination, each individual was also classified as having poor, fair, good or excellent oral health.

\section{Cardiovascular risk factor definition}

Hypertension was defined from the mean of the latest two systolic and diastolic blood pressure (BP) measurements, made using the Omron HEM 705CP oscillometric device. Three measurements were made, at one-minute intervals. Furthermore, the definition of hypertension included previous use of medication to treat hypertension, and systolic $\mathrm{BP} \geq 140 \mathrm{mmHg}$, or diastolic $\mathrm{BP} \geq 90 \mathrm{mmHg}$.
Dyslipidemia was defined as low-density lipoprotein-cholesterol (LDL) $\geq 130 \mathrm{mg} / \mathrm{dl}$ or use of cholesterol-lowering medications. The LDL-cholesterol level was calculated using the Friedewald equation, except for cases with elevated triglyceride levels, when an enzymatic colorimetric assay was used (ADVIA 1200, Siemens). Total high-density lipoprotein-cholesterol (HDL) and triglycerides were analyzed by means of the enzymatic colorimetric assay (ADVIA 1200, Siemens). Ultra-sensitive C-reactive protein (us-CRP) was measured using immunochemistry (nephelometry, Siemens).

Diabetes was defined as a medical diagnosis or use of medication to treat diabetes, or was based on fasting plasma glucose level $\geq 126 \mathrm{mg} / \mathrm{dl}$ or glycated hemoglobin (HbA1C) $\geq 6.5 \%$.

Body mass index (BMI) was calculated by dividing weight in kilograms by height in meters squared. Obesity was defined as $\mathrm{BMI} \geq 30 \mathrm{~kg} / \mathrm{m}^{2}$.

Metabolic syndrome was defined in accordance with the NCEP ATP III criteria (Third Report of National Cholesterol Education Program Expert Panel on Detection, Evaluation and Treatment of High Blood Cholesterol in Adults), ${ }^{31}$ as the presence of three of the following items: waist measurement $>88 \mathrm{~cm}$ for women or $102 \mathrm{~cm}$ for men; HDL-cholesterol $<50 \mathrm{mg} / \mathrm{dl}$ for women or $<40 \mathrm{mg} / \mathrm{dl}$ for men; systolic blood pressure $\geq 130 \mathrm{mmHg}$ or diastolic blood pressure $\geq 85 \mathrm{mmHg}$; serum triglyceride levels $\geq 150 \mathrm{mg} / \mathrm{dl}$; and fasting plasma glucose $\geq 100 \mathrm{mg} / \mathrm{dl}$ (National Cholesterol Education Program Expert Panel on Detection, Evaluation and Treatment of High Blood Cholesterol, 2002).

Venous blood samples were obtained after 12 hours of overnight fasting. The serum obtained after centrifugation was used for hormone and biochemical measurements. Analyses were carried out using an automated analyzer.

\section{Statistical analysis}

Baseline characteristics and CVRF and laboratory data were analyzed in accordance with periodontal disease status (absence of periodontal disease or presence of gingivitis or periodontitis). Categorical variables were expressed as proportions and compared using the chi-square test. Continuous variables were expressed as means (with standard deviation) and compared using analysis of variance (ANOVA), or as medians (with range) using the Kruskal-Wallis test, according to the distribution of the variables. Multinomial logistic regression models were built using periodontal disease status as the dependent variable to evaluate its relationship with each CVRF (hypertension, diabetes, obesity and metabolic syndrome). From this, the OR with its respective 95\% CI was presented in the following models: model 1 (crude); model 2 (adjustment for age and sex); model 3 (adjustment for age, sex, smoking and current alcohol consumption); and model 4 (adjustment for age, sex, smoking and current alcohol consumption and oral hygiene). 
The analyses were performed using the Statistical Package for the Social Sciences (SPSS) version 22.0. For all analyses, a P-value of $<0.05$ was considered significant.

\section{RESULTS}

Table 1 shows the baseline characteristics and the distribution of CVRFs among the 539 adults who were screened at the checkup center during the study period, according to their periodontal disease status. In this population, the mean age was 45 years ( \pm $\mathrm{SD}, 8.8)$, most of the participants were male (82\%) and the educational level was high ( $97 \%$ with college or university degree). It was found that $63.2 \%$ presented periodontal disease (50.6\% with gingivitis and $12.6 \%$ with periodontitis). Individuals with periodontitis were three years older than those without this condition $(\mathrm{P}<0.001)$.

Approximately $70 \%$ of our sample had BMI greater than or equal to $25 \mathrm{~kg} / \mathrm{m}^{2}$ and obese individuals accounted for $20.8 \%$. Other frequently observed CVRFs included dyslipidemia (62.5\%), hypertension (33.2\%), metabolic syndrome (15.4\%) and diabetes $(5.9 \%)$.

We found progressively higher BMI $(\mathrm{P}<0.009)$ and higher frequencies of obesity among individuals with $\mathrm{PD}$ (gingivitis: 22.1\%; periodontitis: $32.4 \%$ ), compared with individuals without PD (15.2\%), P < 0.05. We also noticed higher frequency of diabetes among adults with periodontitis (13.2\%) than among those without $\mathrm{PD}(5.1 \%)(\mathrm{P}<0.05)$. The frequency of $\mathrm{PD}$ did not differ among current smokers (3.0\%), former smokers (7.2\%) and never smokers (89.8\%). Other CVRFs, as well as laboratory parameters such us-CRP levels, were not significantly different between individuals with $\mathrm{PD}$ and those without this condition (Table 1).

Although $88.1 \%$ of the adults screened reported having good oral hygiene habits, which included brushing frequency of at least three times a day (84.3\%), dental flossing frequency of at least once a day $(66.3 \%)$ and low frequency of halitosis (1.3\%), only $25.9 \%$ were considered to have good or excellent oral health. As expected, oral health was progressively worse among individuals with periodontal

Table 1. Baseline characteristics of 539 healthy young and middle-aged adults at a Brazilian health promotion and check-up center, according to periodontal disease

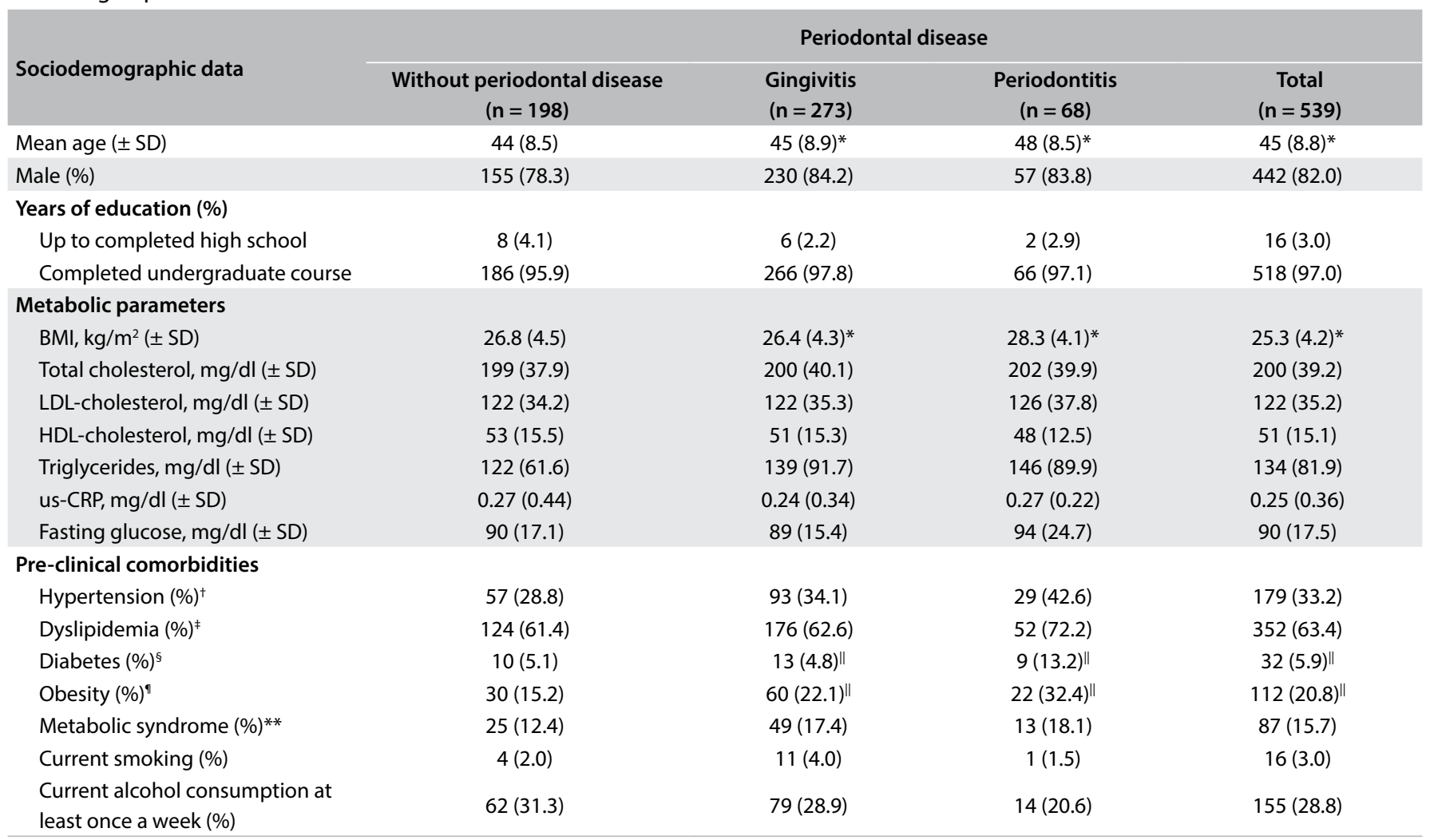

Some proportions might not add up to $100 \%$, due to rounding or missing values (at most $4.7 \%$ ).

${ }^{*}$ P-value $<0.001$ compared with controls (without gingivitis); ${ }^{H}$ Hypertension was defined as systolic blood pressure $\geq 140 \mathrm{mmHg}$ or diastolic blood pressure $\geq 90$

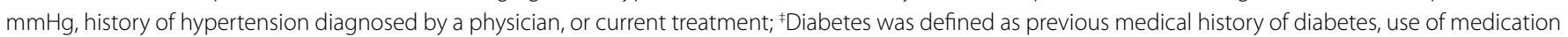
to treat diabetes, fasting plasma glucose $\geq 126 \mathrm{mg} / \mathrm{dl}$, 2-hour plasma glucose $\geq 200 \mathrm{mg} / \mathrm{dl}$, or HbA1C $\geq 6.5 \%$; ${ }^{5}$ Dyslipidemia was assessed in accordance with the National Cholesterol Program-Adult Treatment Panel III (NCP ATP III) guidelines ${ }^{31}$ as follows: LDL-cholesterol $\geq 130 \mathrm{mg} / \mathrm{dl}$ or use of lipid-lowering drug; IIP-value < 0.05 compared with controls; 'Obesity: BMI $\geq 30 \mathrm{~kg} / \mathrm{m}^{2}$; ${ }^{* *}$ Metabolic syndrome was also defined in accordance with NCEP ATP III. ${ }^{31}$ $\mathrm{BMI}=$ body mass index; $\mathrm{LDL}=$ low-density lipoprotein; $\mathrm{HDL}=$ high density lipoprotein; $\mathrm{us}-\mathrm{CRP}=$ ultra-sensitive $\mathrm{C}$-reactive protein Reference group: without periodontal disease. 
disease, and the frequencies of poor oral health were $25.4 \%, 11.9 \%$ and $1.0 \%$ among individuals with periodontitis, with gingivitis and without $\mathrm{PD}$, respectively $(\mathrm{P}<0.001)$. In addition, poor oral hygiene (score 0-3) was more frequent among those with periodontitis (21.2\%) than among those with gingivitis $(13.5 \%)$ or without PD (6.4\%) $(\mathrm{P}<0.001)$.

Among all the comorbidities, obesity (yes, $12.5 \%$, versus no, $5.0 \% ; \mathrm{P}=0.001$ ) and dyslipidemia (yes, $7.7 \%$, versus no, $4.5 \%$; $\mathrm{P}=0.001$ ) were significantly associated with poor oral health. It should be noted that we found the same trend of poor oral hygiene among obese individuals, mainly due to lack of dental flossing, in comparison with non-obese individuals (frequencies of $43.8 \%$ and $31 \%$, respectively; $\mathrm{P}=0.06$ ).

In our regression analyses, obesity was the only emerging risk factor that was consistently associated with pre-existing periodontitis (multivariate OR, 2.36; 95\% CI, 1.23-4.52), even after adjusting for age, sex, smoking and alcohol intake, but not with gingivitis. However, after additional adjustment for oral hygiene score (brushing and dental flossing and the presence of halitosis), this finding was no longer significant (multivariate OR, 1.63; 95\% CI, $0.79-3.37)$. The associations with periodontitis, hypertension and diabetes presented increased OR in crude analyses, but they lost their significance after progressive adjustments for multiple confounders (Table 2). Additional adjustment for oral health instead of oral hygiene did not alter the directions or significance of our findings (data not shown).

\section{DISCUSSION}

Overall, we found relatively high frequencies of periodontal disease (more than 60\%) in our comprehensive screening program, which comprised dental evaluation in conjunction with cardiovascular assessment among young and middle-aged adults, in relation to other populations of the same age. ${ }^{15,26,32,33}$ We did not find any classical cardiovascular risk factors that were independently associated with periodontal disease. Obesity was the risk factor most closely associated with periodontitis, but after multivariate adjustment including oral hygiene and health, this risk was no longer significant.

It is well known that moderate to severe risk of having chronic morbidities can be associated with BMI levels greater than $30 \mathrm{~kg} / \mathrm{m}^{2}$. Despite the heterogeneity of the studies included in a recent systematic review, a pooled OR of 1.81 (95\% CI, 1.42-2.30)

Table 2. Odds ratio (with $95 \% \mathrm{Cl}$ ) for the relationship between periodontal disease and cardiovascular risk factors among 539 healthy young and middle-aged adults at a Brazilian health promotion and check-up center, according to periodontal disease

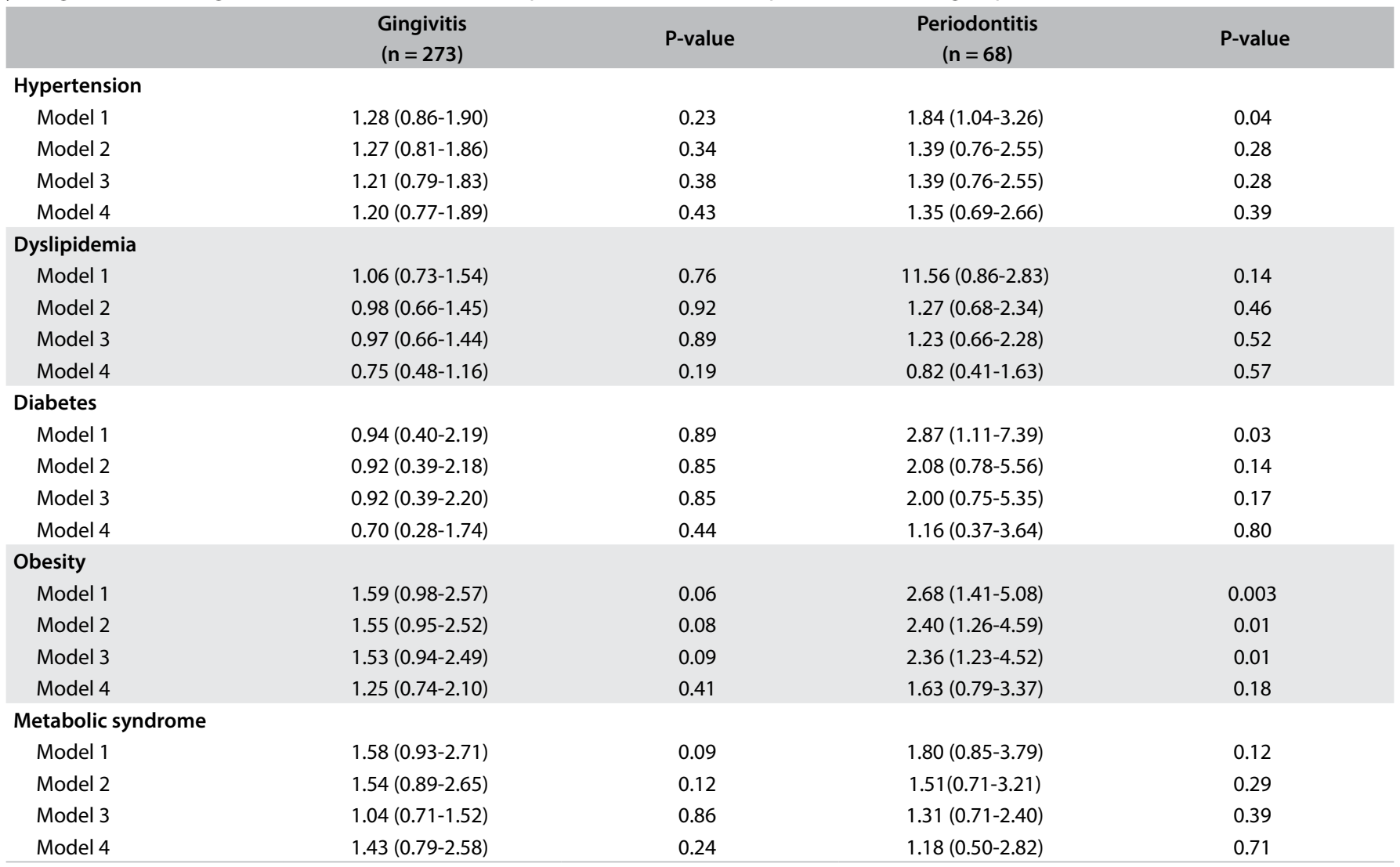

Model 1 = crude; Model 2 = adjustment for age and sex; Model 3 = additional adjustment for smoking and current alcohol consumption (at least once a week); Model 4 = additional adjustment for oral hygiene. $\mathrm{OR}=$ odds ratio; $\mathrm{Cl}$ = confidence interval. 
was reported for the relationship between obesity and periodontitis. ${ }^{34}$ Although several studies have reported the relationship between obesity and periodontal disease, ${ }^{11,13-15,17-21}$ there is no consensus about which pathophysiological mechanism could explain this relationship. Most findings have come from studies with different methodologies for classifying periodontal disease, or with cross-sectional designs or selected or small samples. ${ }^{11,13,14,17-20}$ Some studies were conducted on large and more representative cohorts but still with diverse methodology, particularly relating to the diagnosis of $\mathrm{PD}$, and were restricted to certain sex or age strata. ${ }^{5,12,15,21}$

Very few studies other than ours have considered oral health or hygiene status in their analyses. ${ }^{12,17}$ One of these was a Brazilian population-based birth cohort with a representative sample of 720 subjects in which the association between periodontal disease was determined through oral examination (at the age of 24 years) and obesity was evaluated. Waist circumference and the number of episodes of obesity between the ages of 15 and 23 years were taken to be the main exposures. The evaluation of oral hygiene included use of dental flossing and frequency of brushing. In the crude analysis, gingivitis at two or more teeth was found to be associated with obesity (OR, 1.93; 95\% CI, 1.08-3.43). However, similarly to our findings, after adjusting for other confounders, including oral hygiene, obesity was found to be no longer associated with gingivitis or periodontal pockets in that cohort. ${ }^{12}$ The other study that included oral hygiene in its analysis (tooth brushing) was a cross-sectional study conducted among 372 Japanese adults. ${ }^{17}$ In that study, a dose-response relationship with pack-years of smoking, BMI and periodontitis was described, even after adjusting for confounders. ${ }^{17}$ The main limitations of that study were: self-reported data and the lack of information about use of dental flossing. Of note, in our study, a poor oral hygiene habit was more associated with periodontitis. In fact, lower frequency of dental flossing was observed among obese than among non-obese individuals in our study.

The explanation for the underlying pathophysiological connection between obesity and PD may be that the adverse effects of obesity on the periodontium are mediated through pro-inflammatory cytokines and various other bioactive substances. ${ }^{9}$ In our sample, the total levels of us-CRP were low, with little difference between obese and non-obese adults $(0.22 \mathrm{mg} / \mathrm{dl}$ versus $0.11 \mathrm{mg} / \mathrm{dl}$, respectively; $\mathrm{P}<0.001)$. Other mechanisms that could link these two conditions include the quality of diets that are rich in carbohydrates or saturated fats and/or poor oral hygiene, thereby facilitating the development of local inflammatory processes. ${ }^{35}$ Here, we did not evaluate the role of unhealthy diets. However, our findings suggested that poor oral hygiene, mainly due to not using dental flossing, was associated with obesity, which consequently corroborated the increased risk of periodontitis.
Regarding other CVRFs, we found higher frequencies and increased ORs for the relationship between diabetes and hypertension, but these findings were attenuated in our logistic regression analyses after adjustment for multiple confounders, including oral hygiene.

Previous studies found higher incidence or prevalence of PD, particularly in cases of severe forms of diabetes, compared with the healthy population, including in prospective studies. ${ }^{36-39}$ High risks for the association between diabetes and periodontitis were described in the Gila River Indian Community in Arizona, where the diabetes rates are considered to be the highest worldwide. According to that study, Indians with diabetes presented increased ORs for destructive forms of periodontitis that were around three times higher than in non-diabetics, even after multivariate adjustment, including for oral hygiene. ${ }^{39}$ It is possible that we failed to confirm any high-risk association between PD and diabetes in our logistic analyses because in our sample the frequencies of severe forms of periodontitis and diabetes were much lower and our patients were probably healthier than those included in previous studies. ${ }^{36-39}$

Regarding hypertension, most studies that evaluated the risk of PD also found positive cross-sectional associations s0-42 $^{4 n d}$ some that included oral hygiene habits in their analysis found low ORs (at most 1.5) for the relationship. ${ }^{41,42}$ We also found a positive association with hypertension, but after multivariate adjustments this association was no longer significant. Some characteristics, including the distribution of CVRFs and age, may be associated with these disparities among studies.

Our study has some strength. Our findings depict unique data from a young to middle-aged Brazilian population in which both classical CVRFs and periodontal disease were evaluated through an extensive dental evaluation.

Our study has some limitations. We presented data from a crosssectional assessment, which did not allow us to make causal inferences about the relationship between CVRFs and PD. This was not a population-based study; in fact, our sample was selected from a check-up center and thus we cannot rule out the existence of selection bias that might have compromised generalization of our findings.

\section{CONCLUSIONS}

We did not find any significant association between periodontal disease and traditional cardiovascular risk factors in this young to middle-aged sample.

\section{REFERENCES}

1. Humphrey LL, Fu R, Buckley DI, Freeman M, Helfand M. Periodontal disease and coronary heart disease incidence: a systematic review and meta-analysis. J Gen Intern Med. 2008;23(12):2079-86.

2. Dietrich T, Jimenez M, Krall Kaye EA, Vokonas PS, Garcia RI. Agedependent associations between chronic periodontitis/edentulism and risk of coronary heart disease. Circulation. 2008;117(13):1668-74 
3. Garcia RI, Krall EA, Vokonas PS. Periodontal disease and mortality from all causes in the VA Dental Longitudinal Study. Ann Periodontol. 1998;3(1):339-49.

4. $\mathrm{Xu}$ F, Lu B. Prospective association of periodontal disease with cardiovascular and all-cause mortality: NHANES III follow-up study. Atherosclerosis. 2011;218(2):536-42.

5. Yu YH, Chasman DI, Buring JE, Rose L, Ridker PM. Cardiovascular risks associated with incident and prevalent periodontal disease. J Clin Periodontol. 2015;42(1):21-8.

6. Zahnd G, Vray D, Sérusclat A, et al. Longitudinal displacement of the carotid wall and cardiovascular risk factors: associations with aging, adiposity, blood pressure and periodontal disease independent of cross-sectional distensibility and intima-media thickness. Ultrasound Med Biol. 2012;38(10):1705-15.

7. Batista RM, Rosetti EP, Zandonade E, et al. Retraction: Associação entre doença periodontal e aterosclerose subclínica: estudo ELSA-Brasil [Association between periodontal disease and subclinical atherosclerosis: the ELSA-Brasil study]. Cad Saúde Pública. 2012;28(8):1613.

8. Holtfreter B, Empen K, Gläser S, et al. Periodontitis is associated with endothelial dysfunction in a general population: a cross-sectional study. PLoS One. 2013;8(12):e84603.

9. Schenkein HA, Loos BG. Inflammatory mechanisms linking periodontal diseases to cardiovascular diseases. J Periodontol. 2013;84(4 Suppl):S51-69.

10. Lockhart PB, Bolger AF, Papapanou PN, et al. Periodontal disease and atherosclerotic vascular disease: does the evidence support an independent association?: a scientific statement from the American Heart Association. Circulation. 2012;125(20):2520-44.

11. Pires JR, Dos Santos IP, de Camargo LF, et al. Framingham cardiovascular risk in patients with obesity and periodontitis. J Indian Soc Periodontol. 2014;18(1):14-8.

12. de Castilhos ED, Horta BL, Gigante DP, et al. Association between obesity and periodontal disease in young adults: a population-based birth cohort. J Clin Periodontol. 2012;39(8):717-24.

13. Wood N, Johnson RB. The relationship between smoking history, periodontal screening and recording (PSR) codes and overweight/ obesity in a Mississippi dental school population. Oral Health Prev Dent. 2008;6(1):67-74.

14. Al-Zahrani MS, Bissada NF, Borawskit EA. Obesity and periodontal disease in young, middle-aged, and older adults. J Periodontol. 2003;74(5):610-5.

15. Dalla Vecchia CF, Susin C, Rösing CK, Oppermann RV, Albandar JM. Overweight and obesity as risk indicators for periodontitis in adults. J Periodontol. 2005;76(10):1721-8.

16. Genco RJ, Grossi SG, Ho A, Nishimura F, Murayama Y. A proposed model linking inflammation to obesity, diabetes, and periodontal infections. J Periodontol. 2005;76(11 Suppl):2075-84.

17. Nishida N, Tanaka M, Hayashi $N$, et al. Determination of smoking and obesity as periodontitis risks using the classification and regression tree method. J Periodontol. 2005;76(6):923-8.
18. Saito T, Shimazaki Y, Kiyohara Y, et al. Relationship between obesity, glucose tolerance, and periodontal disease in Japanese women: the Hisayama study. J Periodontal Res. 2005;40(4):346-53.

19. Ekuni D, Yamamoto T, Koyama R, et al. Relationship between body mass index and periodontitis in young Japanese adults. J Periodontal Res. 2008;43(4):417-21.

20. Khader YS, Bawadi HA, Haroun TF, Alomari M, Tayyem RF. The association between periodontal disease and obesity among adults in Jordan. J Clin Periodontol. 2009;36(1):18-24.

21. Kongstad J, Hvidtfeldt UA, Grønbaek M, Stoltze K, Holmstrup P. The relationship between body mass index and periodontitis in the Copenhagen City Heart Study. J Periodontol. 2009;80(8):1246-53.

22. Preshaw PM, Alba AL, Herrera D, et al. Periodontitis and diabetes: a two-way relationship. Diabetologia. 2012;55(1):21-31.

23. Andriankaja OM, Sreenivasa S, Dunford R, DeNardin E. Association between metabolic syndrome and periodontal disease. Aust Dent J. 2010;55(3):252-9

24. Watanabe K, Cho YD. Periodontal disease and metabolic syndrome: a qualitative critical review of their association. Arch Oral Biol. 2014;59(8):855-70.

25. Demmer RT, Papapanou PN. Epidemiologic patterns of chronic and aggressive periodontitis. Periodontol 2000. 2010;53:28-44.

26. Dye BA, Tan S, Smith V, et al. Trends in oral health status: United States, 1988-1994 and 1999-2004. Vital Health Stat 11. 2007;(248):1-92.

27. Helfand M, Buckley DI, Freeman M, et al. Emerging risk factors for coronary heart disease: a summary of systematic reviews conducted for the U.S. Preventive Services Task Force. Ann Intern Med. 2009,151(7):496-507.

28. U.S. Preventive Services Task Force. USPSTF A and B Recommendations, Available from: http://www.uspreventiveservicestaskforce.org/ Page/Name/uspstf-a-and-b-recommendations. Accessed in 2017 (Mar 16).

29. Public Health Agency of Canada. Centre for Health Promotion (CHP). Available from: http://www.phac-aspc.gc.ca/chhd-sdsh/index-eng. php. Accessed in 2017 (Mar 16).

30. Kazmierczak MD, Ciancio SG, Mather M, Dangler LV, Troullos ES. Improved diagnostics: clinical evaluation of a color-coded, polymeric periodontal probe. Clin Prev Dent. 1992;14(4):24-8,

31. National Cholesterol Education Program (NCEP) Expert Panel on Detection, Evaluation, and Treatment of High Blood Cholesterol in Adults (Adult Treatment Panel III). Third Report of the National Cholesterol Education Program (NCEP) Expert Panel on Detection, Evaluation, and Treatment of High Blood Cholesterol in Adults (Adult Treatment Panel III) final report. Circulation. 2002;106(25):3143-421.

32. Eke PI, Dye BA, Wei L, et al. Prevalence of periodontitis in adults in the United States: 2009 and 2010. J Dent Res. 2012;91(10):914-20.

33. Gaio EJ, Haas AN, Rösing CK, et al. Effect of obesity on periodontal attachment loss progression: a 5-year population-based prospective study. J Clin Periodontol. 2016;43(7):557-65. 
34. Suvan J, D'Aiuto F, Moles DR, Petrie A, Donos N. Association between overweight/obesity and periodontitis in adults. A systematic review. Obes Rev. 2011;12(5):e381-404.

35. Al-Zahrani MS, Borawski EA, Bissada NF. Periodontitis and three health-enhancing behaviors: maintaining normal weight, engaging in recommended level of exercise, and consuming a high-quality diet. J Periodontol. 2005;76(8):1362-6.

36. Grossi SG, Genco RJ. Periodontal disease and diabetes mellitus: a twoway relationship. Ann Periodontol. 1998;3(1):51-61.

37. Li Q, Chalmers J, Czernichow S, et al. Oral disease and subsequent cardiovascular disease in people with type 2 diabetes: a prospective study based on the Action in Diabetes and Vascular Disease: Preterax and Diamicron Modified-Release Controlled Evaluation (ADVANCE) trial. Diabetologia. 2010;53(11):2320-7.

38. Demmer RT, Holtfreter B, Desvarieux M, et al. The influence of type 1 and type 2 diabetes on periodontal disease progression: prospective results from the Study of Health in Pomerania (SHIP). Diabetes Care. 2012;35(10):2036-42.

39. Emrich LJ, Shlossman M, Genco RJ. Periodontal disease in non-insulindependent diabetes mellitus. J Periodontol. 1991;62(2):123-31.

40. Holmlund A, Holm G, Lind L. Severity of periodontal disease and number of remaining teeth are related to the prevalence of myocardial infarction and hypertension in a study based on 4,254 subjects. J Periodontol. 2006;77(7);1173-8.

41. Ayo-Yusuf OA, Ayo-Yusuf IJ. Association of tooth loss with hypertension. S Afr Med J. 2008:98(5):381-5.

42. de Oliveira C, Watt R, Hamer M. Toothbrushing, inflammation, and risk of cardiovascular disease: results from Scottish Health Survey. BMJ. 2010;340-c2451.

Acknowledgements: The authors would like to acknowledge the individuals recruited for this study, without whom this work would not have been possible

Sources of funding: None

Conflicts of interest: None

Date of first submission: December 29, 2016

Last received: January 18, 2017

Accepted: January 30, 2017

\section{Address for correspondence:}

Alessandra Carvalho Goulart

Centro de Acompanhamento da Saúde e Check-up, Hospital

Sírio-Libanês (HSL)

Rua Joaquim Floriano, 533, 10 andar

Itaim Bibi — São Paulo (SP) — Brasil

CEP 04534-011

Tel. (+55 11) 2344-3135

E-mail: alessandra.cgoulart@hsl.org.br 